\title{
Research Paper: Explaining the Drought Management Pattern in Rural Areas (Case Study: Eslamabad Gharb crossuark district)
}

\author{
Bahman Shafiee $^{1^{*}}$, Hamid Barghi ${ }^{2}$, Yusef Ghanbari ${ }^{2}$
}

1. PhD Candidate, Department of Geography and Rural Planning, Faculty of Geographical Sciences and Planning, University of Isfahan, Isfahan, Iran 2. Associate Professor, Department of Geography and Rural Planning, Faculty of Geographical Sciences and Planning, University of Isfahan, Isfahan, Iran.

\begin{tabular}{|l|l|}
\hline $\begin{array}{l}\text { Use your device to scan } \\
\text { and read the article online }\end{array}$ & $\begin{array}{l}\text { Citation: Shafiee, B., Barghi, H., \& Ghanbari, Y. (2020). Explaining the Drought Management Pattern in Rural Areas } \\
\text { (Case Study: Eslamabad Gharb district). Journal of Sustainable Rural Development, 4(2), 289-306. https://doi.org/10.32598/ } \\
\text { JSRD.4.2.14 }\end{array}$ \\
dol: & https://doi.org/10.32598/JSRD.4.2.14
\end{tabular}

\section{Article info:}

Received: 10 July 2019

Accepted: 06 Feb. 2020

\section{Keywords:}

Drought Management, Rural Areas, Eslamabad Gharb, Iran

\section{ABSTRACT}

Purpose: The purpose of this study was to analyze the status of effective factors on drought management in rural areas, which was done in rural areas of Eslamabad Gharb.

Methods: The statistical population of the study consists of all members of over 20 households in seven rural districts. Using the Cochran formula, 374 of them (located in 21 villages) have been studied as examples. To analyze the data, the confirmatory factor analysis method was used in SPSS 22 and Smart-Pls software. Finally, in the qualitative paradigm, using the data-based approach, the open coding results indicated the existence of key terms in the form of 44 concepts, which were then transformed into four main categories at the axial coding stage. In the last step, namely selective coding, while defining the core category, the final model of the foundation data was presented.

Results: The results of this study showed that the economic dimension of drought management, with a 17.642 significance, shows drought management at a confidence level of $0.95 \%$. The path coefficient between these two is 0.251 , which suggests that the economic dimension of 0.251 percent explains directly the drought management.

Conclusion: Accordingly, first, government measures should be taken to establish technical, institutional and service infrastructure in the region, and then, based on the capacity of the region, taking into account the prestigious rural population, in line with public participation, as well as the prevention of migration, basic measures should be taken.

\section{Introduction}

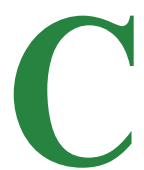

limate change and the quantitative and qualitative reduction of water resources usable on the one hand, and the increas- ing world population, and water demand, on the other hand, have complicated the management of water resources. Iran is also among the areas that already faces a water crisis, due to its belt location and lack of proper consumption patterns and is expected to enter a cata-

* Corresponding Author:

Bahman Shafiee, PhD

Address: Department of Geography and Rural Planning, Faculty of Geographical Sciences and Planning, University of Isfahan, Isfahan, Iran.

Tel: +98 (918) 6829255

E-mail: m28760297@gmail.com 
strophic phase in the coming years. Therefore, having tools to support the efficient management of water resources, will be the requirement of water management in the country. In the meantime, drought, as a natural phenomenon, disturbs the balance between supply and demand. However, due to the inevitability of this phenomenon and its continuing nature, its effectiveness can be reduced by effective management. In general, in dealing with any natural hazard, two types of management can be applied; one is risk management and the other is crisis management (Fard Moradinia \& Soleimanzadeh, 2016: 6). Natural hazards have been an inseparable part of human life and have continuously existed since the creation of mankind (Khamri, 2012: 1). The first step to properly cope with the drought and its consequences is to understand this phenomenon and its effects in different dimensions in order to be able to draw up effective strategies in this regard (Hoseini et al., 2016: 95). In recent years, due to climate change, globally, widespread drought-related phenomena, in terms of severity, frequency, increase, and duration, have emerged worldwide (Sivakumar, 2012; Peterson et al., 2013). The occurrence of droughts in various parts of the world shows the vulnerability of all nations to weather events (Poor Taheri et al., 2013: 47). Iran is not an exception to this rule and has always been exposed to natural disasters such as floods, droughts and earthquakes, and out of 40 disasters that happen in the world, 31 occur in Iran. Therefore, Iran is on the list of the top 10 disaster-prone countries in the world (Buzarjomhori \& Javanshiri, 2015: 36). Drought, as the most complex natural disaster, affects a large number of rural inhabitants with a farm-dependent economy (Adeli et al., 2014: 131). Today, drought is considered one of the most important natural hazards that have direct and indirect consequences, especially in rural areas. Consecutive droughts have led to the disappearance of agriculture, and the disappearance of villages whose inhabitants have migrated to cities (Barghi et al., 2018: 143). Due to their close relationship with the natural environment and their limited opportunities, rural communities have long been exposed to destructive natural forces, especially droughts, and farmers in each area are experimenting with measures to adapt and counteract them (Gholami et al., 2014: 611). The rural economy has a significant reliance on agricultural activities, so the radius of the drought phenomenon in rural areas is more than elsewhere, and the consequences of droughts in these areas are greater than in urban areas, as one of the main sources of household food supply. The village is a self-employed agricultural, horticultural and livestock production center (Esmaeili \& Khodadad, 2017: 25).
Kermanshah Province is the sixth province of the country in terms of drought problems. Due to droughts, about 550 villages in the province suffer from a water deficit, and the damage caused to the province due to drought and frost in 2008 was announced to be more than 800 billion Tomans (Javanmardi, 2009). Based on the statistical analysis, according to the synoptic station of Eslamabad Gharb, it is observed that from 1986 to 2016, 14 years of drought have been observed in the county level, of which 8 years are the normal drought, 4 years are moderate drought, and 2 years are severe droughts, which have occurred in recent years, often with severe and moderate droughts. Eslamabad Gharb has moderate mountainous water resources, relatively cold winters, and mild summers (Strategic Development Plan of Eslamabad Gharb district, 2005: 6). Droughts have had a devastating impact on the economy and livelihoods of the villagers, and the lack of proper management, both before, during, and after the occurrence of drought, has reduced agricultural production and livestock (carcass weight), and has led to livestock losses, reduced income from livestock, employment rate, per capita production, the production efficiency of each livestock, groundwater reserves, and the quality of water resources. Also, the lack of a suitable model for monitoring and managing drought has added to problems in this field. The city has many villages, and the source of income of most of them, such as livestock and agriculture, is dependent on water resources. In recent years, the occurrence of multiple droughts has caused their source of income to fall into crisis, which requires the adoption an approach that would provide comprehensive guidance on droughts, and evaluate and describe their proportional planning patterns. In recent years, drought has caused a great deal of damage to human societies, especially rural areas, due to their severe dependence on water and agricultural land, which is the case in areas where agriculture and livestock are the main activity and the high agricultural lands have a more serious significance, including the Eslamabad Gharb district and its villages, and in recent years drought has led to the destruction of agricultural land, reduced crop production, reduced livestock activities and has even led to migration from villages. In order to prevent drought damage and manage it appropriately, it is necessary to study the status and management of drought in rural areas in a community survey. Therefore, the present study seeks to answer the following question.

What are the economic, social, environmental and institutional-physical effects on drought management in the studied rural areas?

Crisis management perspective 
1. Traditional view: This view considers crisis to be essentially a negative and undesirable phenomenon that must be avoided in any way. According to this view, crises have a completely destructive and deterrent nature.

2. Natural Law Perspective: Proponents of this view consider crisis as part of the nature of human life, whether we like it or not, but their attitude is still a negative view of the crisis. They do not try to deny and avoid the crisis, but rather take a perfectly reasonable stance.

3. Interactive View: This view has a very different view of the crisis, and, unlike previous views, looks at the positive, believing that not only it should not be rejected or denied, but also welcomed at times. Unlike the first view, which is the stillness and stability, and the second view, the interactive view is the dynamic view, and the mobility perspective.

According to the aforementioned theoretical approaches, what can be considered in the theoretical framework of this research is the interactive perspective, the dynamics perspective and the mobility perspective (Roshandel Arbatani et al., 2009).

Several studies have been conducted to address the factors affecting drought and its impacts in different urban and rural areas, which are referred to in some cases. Generally speaking, Sengestam (2009) and Cooper et al. (2008) argue that access to various types of capital determines coping strategies. Folkman (2018), in a study on drought management and its factors, concludes that coping methods vary in different countries, and depend on the capabilities and capital as well as the individuals' ability to solve problems. Sadeghlou et al. (2017), in a paper, assess the level of knowledge and awareness of villagers about the management of drought crisis (case study: rural inhabitants of Mian Khaf village of Khaf district). They suggest that sample rural households, having four components of crisis management knowledge, and villagers' knowledge in general regarding drought crisis management are below the ideal numerical average of 3. Also, using the Cooper prioritization model, among the studied villages, the assessment of knowledge about the management of drought crisis management was carried out, and the Fayender village with the highest score ranked first, the village of Varab ranked second, and the village of Mahabad had the lowest rank. Alipour et al. (2013), in a study titled "Drought effects on the socioeconomic status of farmers in Nehbandan", concluded that the effects of drought on farmers' economic situation were determined by five factors: increased production costs, reduced wheat production, farmers' reduced economic ability, farmers' reduced future productive capacity and leaving the agricultural sector, and social effects of drought on farmers' situation were determined by five factors: increased social harm, reduced health and nutrition levels, psychological effects of drought, the occurrence of social disparities, and creating poverty in society. Mohammadi Yeganeh et al. (2012), in an article on the effects of drought on the economy of rural areas of Abarkuh (during the period of 19962006), concluded that during this period, the city was in a drought situation. Also, the results of factor analysis, and the study of crops and gardens indicated that the successive droughts have caused irreparable economic losses in the villages of this city. Elfaigh (2000) studied farmers in Sudan and concluded that the use of droughtresistant varieties, early seeding, using unexpected rainfall, increasing the spacing between the rows and using mixed crops have been effective in reducing the vulnerability of farmers. Cook et al. (2007), in a research entitled North American Drought: Rebuilding Factors and Consequences, concluded that the impact of drought on a specific environment, perhaps less significant, is the high cost of drought economics. There is also no debate about the drastic social effects of drought on farmers and livestock farmers who were forced to leave the flat land in order to find better conditions elsewhere. Urkia et al. (2008), in a research entitled Analysis of the Socio-Economic and Ecological Effects of Drought, concluded that wastewater recycling was an option for water reuse and optimization of water availability, and the choice of appropriate technology and sewage treatment were the most important steps in the planning of the water remediation system in order to deal with drought. Shewmake (2008), in a study entitled Vulnerability and Climate Change Effects in South Africa, states that livestock sales, borrowing from relatives, lending, immigration, non-agricultural activities, and reduced food consumption, are among strategies, adopted by farmers' families that face drought and deal with it in order to minimize the vulnerability. Nagaraja et al. (2009), in a study entitled Drought Effects on Agriculture: Challenges for Poor Farmers in the Karnataka Region, while studying the effects of drought on farmers' economic conditions, concluded that the persistence of droughts led to an increase in exploitation of groundwater and increased the likelihood of fire in dry and semi-arid areas, and the annual income of households has dropped by half in dry years.

Naveen et al. (2014), in a study entitled Drought-related vulnerability and drought-related policies in the semi-arid parts of Asia, addressed drought damage in semi-arid Asian regions, and the research results showed 
that drought incidence had lots of social and economic effects, such as reduced yields, reduced employment, reduced capital, reduced income, and malnutrition.

An overview of the above studies shows that the drought management situation varies from region to region, depending on the different economic, social, environmental, institutional-factual, climatic, etc. conditions. So far, research targeting households has not been addressed, and a series of effective factors in drought management has been addressed in the region. In previous studies, the issue of drought management and its effects on rural life has not been addressed. Therefore, the researchers in this study, aware of the studies carried out and also considering the social, economic and environmental conditions of the study area, seek to analyze the status of effective factors on drought management among villagers in Eslamabad Gharb.

\section{Methodology}

The population under study was 13656 pindividuals living in more than 20 households (due to agricultural land, topographic conditions and environmental structure), based on population and housing census 2016, in rural areas of Eslamabad Gharb (seven villages) during the years 1986-2017 who had been exposed to drought. In the qualitative part, the database theory method was used. 25 experts including professors, administrative executives, Agricultural Jihad Organization experts, natural resources, regional water and meteorological department were interviewed. The study was conducted using snowball sampling method to collect data. In this section, indepth interviews were conducted with individuals.

In snowball sampling method, experts are asked to identify others who are familiar with the subject of research. This sampling method is a non-probability sampling method and seems appropriate when members of a group or community are not easily identifiable; in other words, it is appropriate when the group or community of the case study is very scarce, or a small part of a very large community. In this way, the researcher identifies people, and after receiving the information, asks them to identify the person or others. Therefore, this method is gradual and can be effective in selecting individuals, especially those specialized. This method of sampling will continue until the interviewee (answers) reaches saturation, and from then on, the answers (interviewees) will duplicate, thus stopping the gathering of information. According to the studied geographical conditions, the sampling method in the quantitative section is stratified with a proportional assignment. 21 villages were consid- ered as target villages due to the environmental structure (Table 1), and the samples were randomly selected and the questionnaire was given to them. The sample size was 374 heads of households, obtained by the Cochran formula.

$$
\begin{aligned}
& n=\frac{\frac{(1.96)^{L}(0.5)(0.5)}{(0.05)^{2}}}{1+\frac{1}{13656}\left(\frac{(1.96)^{2}(0.5)(0.5)}{(0.05)^{2}}-1\right)}=373.6754 \cong 374 \\
& n=\frac{\frac{t^{2} p q}{d^{2}}}{1+\frac{1}{n}\left(\frac{t^{2} p q}{d^{2}}-1\right)}
\end{aligned}
$$

A researcher-made questionnaire consisted of 44 questions ( 7 economic questions, 15 social questions, 7 environmental questions, 15 institutional-infrastructure questions), and the hidden variables of drought management, which were measured using the four dimensions mentioned. They were used as the main tool for collecting data. The Theory Measurement Scale, based on the Likert Five Optional Spectrum, was used which starts with "very little" and ends with "very much," and the method of scoring questions is from a score of 1 to a score of 5. Content validity was used to confirm the validity of the measurement tool. Content validity is created by ensuring compatibility between metrics and existing literature. This validity was obtained by a survey of professors. Also, in order to determine the reliability of the questionnaire, two criteria (Cronbach's alpha coefficient and composite reliability coefficient) were used, according to Fornell and Locker (1981: 181). Regarding Cronbach's alpha coefficient, all variables in this research are higher than the minimum value $(0.7)$. Composite reliability, unlike Cronbach's alpha, which implicitly assumes that each index has the same weight, relies on the true factor load of each structure, and therefore provides a better benchmark for reliability. The composite reliability should be somewhat higher than 0.7 to express the internal stability of the structure (Fornell \& Locker, 1981). In Table 1, the results of the reliability of the measured instrument are presented. Also, in order to analyze the data, statistical (inferential) methods were used in SPSS 22 and Smart-Pls software. 
The study area

Eslamabad Gharb, between 33 degrees and 43 minutes, up to 34 degrees and 21 minutes north latitude, 46 degrees and 17 minutes, up to 47 degrees and 1 minute east, is located in the Greenwich Meridian. This city is located in a mountainous area, with moderate mountainous climate. It has relatively cold winters and mild summers (Strategic Development Plan of Eslamabad Gharb district, 2005). The distance from the mentioned city to the center of the province is $60 \mathrm{~km}$, and the height from the sea level, is 1335 meters (Andisheh Sabz Consulting Engineers, 2010). According to the census of 2016, its population is 140164 and it has two parts: central and
Hamil. Hamil district has three villages, and the central part has four villages. Out of the 21 rurals studied, 10 rurals in Hamil district and 11 rural districts are located in the central part (Figure 1).

\section{Findings}

Based on the statistical data analysis, according to the Eslamabad-Gharb synoptic station, it is observed that from 1986 to 2016, 14 years of drought have been observed in the county, of which 8 years are the normal drought, 4 years are moderate drought and 2 years are severe droughts (Table 2).

Table 1. Instrumentation reliability

\begin{tabular}{ccc}
\hline Research variables & Composite reliability coefficient & Cronbach's alpha \\
\hline Economic & 0.873233 & 0.821880 \\
Social & 0.848706 & 0.811284 \\
Environmental & 0.753233 & 0.633858 \\
Infrastructure- Foundation & 0.854690 & 0.820994 \\
Drought Management & 0.927096 & 0.811284 \\
\hline
\end{tabular}

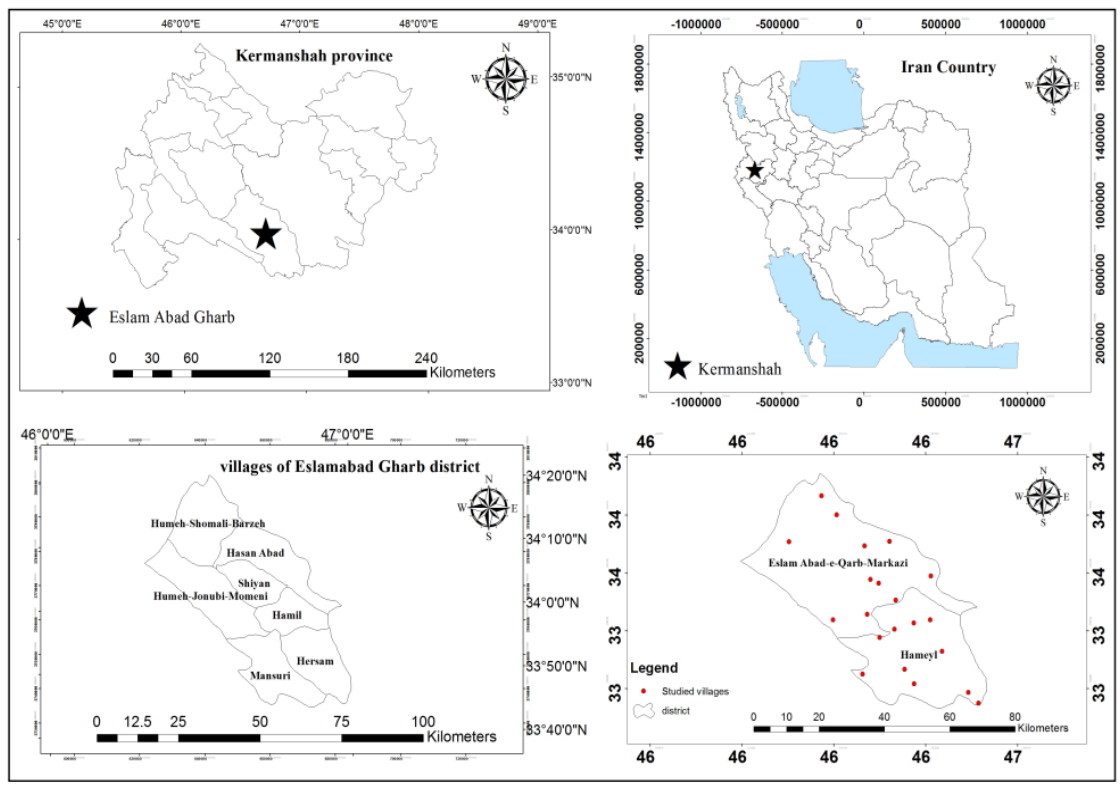

Figure 1. Map of the study area, and sample villages 
Table 2. Rainfall of Synoptic Station of Eslamabad Gharb, and Standardized Rainfall Index calculation, during the period 1986-2016

\begin{tabular}{|c|c|c|c|c|c|c|c|c|c|c|c|c|c|c|}
\hline degree & Spi & March & Feb & Jan & Dec & Nov & Oct & Sep & Aug & Jul & Jun & may & Apr & year \\
\hline $\begin{array}{l}\text { Medium Wet } \\
\text { Periods }\end{array}$ & 1.329220745 & 105.4 & 112.5 & 100.4 & 74.3 & 136.1 & 12.2 & 0 & 0.4 & 0 & 0.8 & 14.2 & 65.2 & 1987 \\
\hline Mild drought & -0.129252225 & 124.6 & 71.6 & 71 & 58.4 & 22.8 & 28.7 & 0 & 0 & 0 & 5 & 33 & 36.8 & 1988 \\
\hline Normal & 0.886499855 & 51.2 & 100 & 94.5 & 127.2 & 93.8 & 0.1 & 0 & 0 & 0 & 0 & 23.4 & 78.3 & 1989 \\
\hline Mild drought & -0.950374177 & 140.7 & 37 & 96.6 & 7.4 & 25.9 & 0 & 0 & 0 & 0 & 0 & 11.1 & 29.9 & 1990 \\
\hline Normal & 0.843063089 & 165.9 & 69.9 & 62 & 163.6 & 20.2 & 18.6 & 0 & 0 & 0 & 0 & 1 & 62.1 & 1991 \\
\hline Normal & 0.379459138 & 100.1 & 13.4 & 115.1 & 90.1 & 59.7 & 0 & 0 & 0 & 0 & 3.4 & 72.6 & 53.4 & 1992 \\
\hline $\begin{array}{l}\text { Medium Wet } \\
\text { Periods }\end{array}$ & 1.20726367 & 86.4 & 69.3 & 84.3 & 63.1 & 155 & 0 & 0 & 0 & 0 & 5.4 & 115.8 & 27.6 & 1993 \\
\hline $\begin{array}{l}\text { Intense Wet } \\
\text { Periods }\end{array}$ & 1.619912952 & 61.7 & 42.2 & 37.9 & 192.9 & 151 & 107.3 & 1.2 & 0 & 0 & 0 & 30.5 & 31.6 & 1994 \\
\hline Mild drought & -0.175194959 & 138.4 & 63.9 & 46.4 & 18.3 & 11.2 & 0 & 0 & 0 & 0 & 24.9 & 43.4 & 76.9 & 1995 \\
\hline Mild drought & -0.78999227 & 86.4 & 24.4 & 62.4 & 41.8 & 4.5 & 0.4 & 0 & 0 & 0.3 & 0 & 34.7 & 112.9 & 1996 \\
\hline $\begin{array}{l}\text { Medium Wet } \\
\text { Periods }\end{array}$ & 1.436142017 & 129.9 & 98.4 & 63.3 & 68.4 & 115.9 & 16.5 & 0 & 0 & 0 & 0.5 & 47.1 & 94.3 & 1997 \\
\hline Mild drought & -0.354789282 & 49.6 & 73.3 & 90 & 0 & 42.2 & 0 & 0 & 3.1 & 0 & 1 & 63.4 & 97.3 & 1998 \\
\hline Intense drought & -1.753954359 & 4 & 59 & 65 & 38.2 & 25.3 & 0 & 0 & 0.7 & 12.1 & 0 & 9.5 & 38.6 & 1999 \\
\hline Mild drought & -0.855982742 & 31.8 & 72.4 & 51.1 & 104.4 & 15.3 & 28.2 & 0 & 0 & 0 & 0 & 18.6 & 38.1 & 2000 \\
\hline Moderate drought & -1.021376584 & 68.8 & 87.3 & 60.9 & 97.1 & 26 & 12.9 & 11.5 & 0.4 & 0 & 0 & 3.4 & 48.1 & 2001 \\
\hline Normal & 0.072895804 & 52.2 & 92.2 & 50.7 & 94.4 & 47.9 & 0.1 & 0 & 0 & 0 & 0 & 6 & 127.6 & 2002 \\
\hline Mild drought & -0.12424029 & 7.1 & 87.8 & 74.9 & 166.4 & 51.7 & 0.4 & 0 & 0 & 0 & 0.8 & 14.7 & 43.7 & 2003 \\
\hline $\begin{array}{l}\text { Intense Wet } \\
\text { Periods }\end{array}$ & 1.603206504 & 189.4 & 115.6 & 98.4 & 44 & 80.9 & 0 & 0 & 0 & 0 & 0.5 & 63.1 & 62.4 & 2004 \\
\hline Normal & 0.175640464 & 20.6 & 234.7 & 119.2 & 31.4 & 39 & 0.3 & 0 & 0 & 0 & 0 & 22.4 & 15.8 & 2005 \\
\hline Normal & 0.267525932 & 50.4 & 74.6 & 42.2 & 32.5 & 121.9 & 23.3 & 0 & 0 & 0 & 0.9 & 40.5 & 108.1 & 2006 \\
\hline Moderate drought & -1.142498337 & 49.1 & 58.9 & 33.5 & 30.1 & 4.2 & 1 & $\sigma$ & 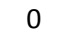 & 0 & 0.6 & 52.2 & 96 & 2007 \\
\hline Intense drought & -1.575195358 & 21.2 & 49.2 & 26.1 & 52.6 & 96.3 & 0 & 22.1 & 0 & 0 & 0 & 5.9 & 0.4 & 2008 \\
\hline Normal & 0.146404179 & 83.3 & 78.4 & 31.2 & 32.9 & 149.7 & 4.1 & 15.2 & 0 & 0 & 0.9 & 12.4 & 71.8 & 2009 \\
\hline Moderate drought & -1.20514752 & 21.2 & 68.3 & 33 & 38.5 & 23.1 & 1. & 0 & 0.1 & 0 & 0.2 & 87.9 & 44.4 & 2010 \\
\hline Normal & 0.075401772 & 45.8 & 91.7 & 21 & 1.2 & 175.8 & 0.3 & 0 & 0 & 0.3 & 0 & 76.1 & 59.2 & 2011 \\
\hline Mild drought & -0.968751271 & 13.6 & 69.2 & 49.8 & 85.7 & 60.1 & 0.1 & 0 & 0 & 5.4 & 0.4 & 3 & 59.1 & 2012 \\
\hline Normal & 0.233277712 & 97.1 & 78.4 & 52.2 & 73.6 & 132.8 & 0 & 0 & 0 & 0 & 0.3 & 49.5 & 6.4 & 2013 \\
\hline Moderate drought & -1.26362009 & 46.5 & 20.7 & 31.2 & 38.2 & 61.5 & 40.9 & 0 & 1.2 & 0 & 3.7 & 25 & 42.2 & 2014 \\
\hline $\begin{array}{l}\text { Medium Wet } \\
\text { Periods }\end{array}$ & 1.389363961 & 85.2 & 68.3 & 67.7 & 60.4 & 266.2 & 3.4 & 4.7 & 0 & 5 & 0 & 9.7 & 58.1 & 2015 \\
\hline Normal & 0.645091672 & 112.4 & 113.2 & 97.3 & 37.7 & 1.6 & 0 & 0 & 0 & 0 & 0 & 39.8 & 137.6 & 2016 \\
\hline Normal & 471.9 & 47.4 & 155 & 36.9 & 15.6 & 60.2 & 0 & 0 & 0.2 & 0 & 0 & 21.5 & 135.1 & 2017 \\
\hline
\end{tabular}




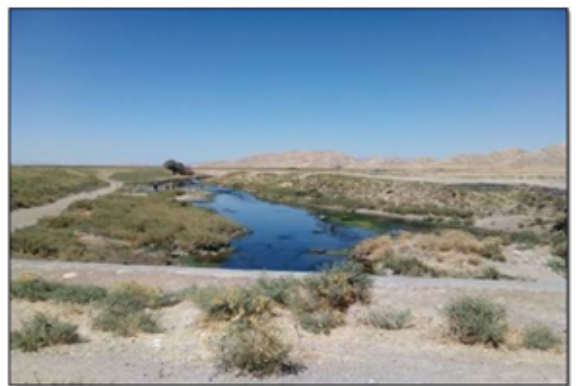

A: Reduction of Dubai to the level of Chaghakabud village (climate and hydrological drought)

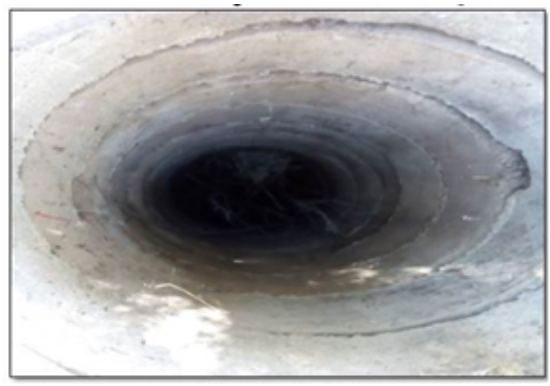

C: Drying of well water due to drought in 2017, (hydrological and climatic drought)

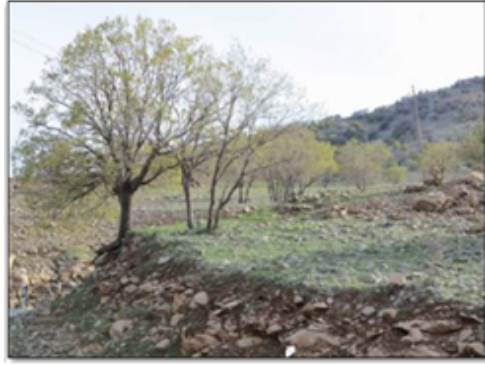

B: Dry Oak Trees (Climate Drought

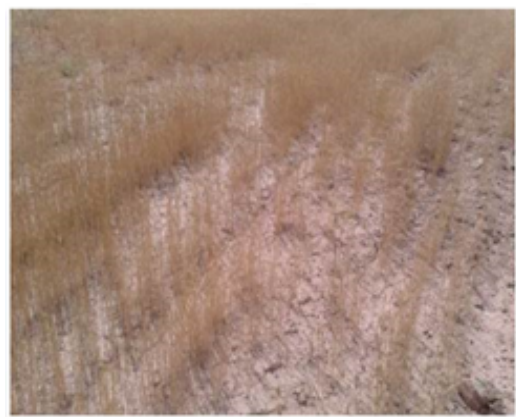

D: Drying of crops, in the village of Tuh Sorkhak Olya, 2014 (Agricultural and Climatic Drought).

Figure 2. Views of the droughts in the villages under study. (Research Findings, 2019)

Analysis of Effective Factors on Drought Management

The power of the relationship between the agent (hidden variable) and the visible variable is shown by the factor load. The factor load is between zero and one. It is observed that all observed variables have positive and significant regression coefficients with their own scales, and the magnitude of these coefficients is relatively high for all cases. The results of Table 3 show that, in the economic dimension, lending and low-interest loans and grants to drought-affected layers, with a factor of 0.910 , subsidized subsidies, and support for investment and entrepreneurship in drought areas, with a factor of 0.910 , and the availability of suitable and permanent jobs to cope with drought, with a factor of 0.744 , in social dimension, to reduce the drought consequences, with a factor of 0.697 , increase in investment incentives to cope with drought, in the local population, with a factor of 0.646 , and the use of drought tolerant cultivars, and a change in the pattern of cultivation, with a factor of 0.635 , in the lifetime, fighting against the onset of pests and plant diseases, with a factor of 0.779 , the reconstruction and optimization of existing resources, which "depends heavily on work, materials and land resources" (Rudenko et al., 2017) with a factor of 0.688 , and avoidance of water loss, and inappropriate consumption practices, with a factor of 0.651 , and in the institutional-social dimension, the specificity of the ways of ownership of the sources of production (such as pasture land and crops), the replacement of coping methods, and alternatives to droughts, instead of the opposite with its consequences, and access to materials and infrastructures and production technologies, respectively, with factor loadings of 0.794.0.723 and 0.722 , are the most important components affecting the transition, in drought management in rural areas.

The first step in analyzing the model is to plot it on the Smart-Pls front page. The dangers of hidden variables should be related to questions. Drought management variables are linked to four dimensions, namely, economic, social, environmental and institutional-physical dimensions, and these dimensions are related to their respective questions, so questions that are used to measure these four dimensions should be the hidden variables of drought management, hence the queries 1-44, taken from the indicators window, and the drought management variable, connecting the hidden drought management questions to the dye causes the color of this variable to be blue. Since the relationship between the questions and the hidden variables is not analyzed, with the right click on the drought management variable and the choice of the Hide/Show Measurement Model option, we hid these questions (Davari \& Rezazadeh, 2016: 160-161). In this section, using the structural model test, we seek to analyze the results. 
Table 3. Analysis of the Status of Factors Affecting Drought Management in Rural Areas in Eslamabad Gharb

\begin{tabular}{|c|c|c|c|}
\hline Variable & Questionnaire questions & $\begin{array}{l}\text { Factor } \\
\text { load }\end{array}$ & T-Test \\
\hline \multirow{7}{*}{ Economic } & $\begin{array}{l}\text { 1- Convenient access to the goods and services needed for agricultural products and handi- } \\
\text { crafts, for the proper use of water and soil }\end{array}$ & 0.711 & 24.881 \\
\hline & 2. Proper management of drought by the government & 0.527 & 14.887 \\
\hline & 3- The presence of suitable and permanent jobs to deal with drought & 0.774 & 33.228 \\
\hline & $\begin{array}{l}\text { 4. Different sources of production, along with the consequences of drought, despite the lack } \\
\text { of coping schemes }\end{array}$ & 0.612 & 12.976 \\
\hline & 5- Providing the necessary funding in the budgeting system for drought management plans & 0.375 & 6.108 \\
\hline & 6. Granting low-interest loans and grants for drought-affected groups. & 0.910 & 103.592 \\
\hline & $\begin{array}{l}\text { 7. Paying subsidies, and supporting investment and entrepreneurship, in drought-affected } \\
\text { areas }\end{array}$ & 0.910 & 103.593 \\
\hline \multirow{15}{*}{ social } & 8. Participation of villagers and tribes in relevant planning, in the field of drought management & 0.377 & 7.150 \\
\hline & $\begin{array}{l}\text { 9. The existence of social institutions, in rural and nomadic areas, for addressing the affairs on } \\
\text { behalf of people, including in the field of drought management }\end{array}$ & 0.540 & 15.425 \\
\hline & 10. Constraints on the reduction of drought consequences & 0.697 & 22.608 \\
\hline & 11. The evolution of traditional methods of agriculture and livestock husbandry & 0.628 & 17.544 \\
\hline & 12. The suitability of commonly used methods in rural areas & 0.618 & 18.423 \\
\hline & $\begin{array}{l}\text { 13. The existence of an appropriate irrigation system and the required infrastructure in the } \\
\text { agricultural sector }\end{array}$ & 0.363 & 8.262 \\
\hline & $\begin{array}{l}\text { 14. High level of knowledge, skills and technology of farmers in the field of water resources } \\
\text { management }\end{array}$ & 0.505 & 9.131 \\
\hline & 15. Benefiting from drought-resistant cultivars, and changing the cultivar pattern & 0.635 & 18.638 \\
\hline & $\begin{array}{l}\text { 16. Improving educational programs in the field of water resources management in the agri- } \\
\text { cultural sector }\end{array}$ & 0.553 & 9.153 \\
\hline & 17. Development of indigenous knowledge & 0.514 & 12.262 \\
\hline & 18. Increasing incentives to invest in drought among locals & 0.646 & 18.249 \\
\hline & $\begin{array}{l}\text { 19. Preventing disintegration and creating unity among individuals and rural and nomadic } \\
\text { communities }\end{array}$ & 0.330 & 5.570 \\
\hline & $\begin{array}{l}\text { 20. Promoting and educating the techniques and methods for the correct circulation, distribu- } \\
\text { tion and use of irrigation water }\end{array}$ & 0.504 & 8.934 \\
\hline & 21. Developing irrigation infrastructures and networks and water-compatible local conditions & 0.449 & 6.889 \\
\hline & $\begin{array}{l}\text { 22. Using the capacity of research institutes, academic centers and executive agencies to cope } \\
\text { with droughts }\end{array}$ & 0.418 & 8.394 \\
\hline \multirow{7}{*}{ environmental } & 23. Reconstruction and optimization of available resources & 0.688 & 18.835 \\
\hline & 24. Avoiding water loss and inappropriate consumption practices & 0.651 & 20.409 \\
\hline & 25. Storage of water from rain and snow & 0.378 & 4.318 \\
\hline & 26. Increasing protected areas and preventing their destruction & 0.330 & 3.632 \\
\hline & 27. Preventing soil erosion and desertification & 0.551 & 15.961 \\
\hline & 28. Fighting the onset of pests and plant diseases & 0.779 & 26.018 \\
\hline & 29. Preserving the diversity of plant species, and preventing them from disappearing & 0.432 & 8.811 \\
\hline
\end{tabular}


Table 3. Analysis of the Status of Factors Affecting Drought Management in Rural Areas in Eslamabad Gharb

\begin{tabular}{|c|c|c|c|}
\hline Variable & Questionnaire questions & $\begin{array}{l}\text { Factor } \\
\text { load }\end{array}$ & T-Test \\
\hline \multirow{15}{*}{$\begin{array}{l}\text { Institutional- } \\
\text { infrastructure }\end{array}$} & 30. Development of a comprehensive and strategic plan for integrated drought management & 0.607 & 13.763 \\
\hline & 31. Development of drought management infrastructure in rural and nomadic areas & 0.508 & 12.515 \\
\hline & $\begin{array}{l}\text { 32. Replacement of coping methods, and alternatives to drought, instead of the opposite with } \\
\text { its consequences }\end{array}$ & 0.723 & 36.781 \\
\hline & 33. Estimating Drought Time & 0.453 & 3.739 \\
\hline & $\begin{array}{l}\text { 34. The appropriateness of the public services and insurance system in dealing with drought } \\
\text { complications }\end{array}$ & 0.631 & 27.872 \\
\hline & 35. Determination of the ownership of production resources (such as pasture land and crops) & 0.794 & 39.326 \\
\hline & 36. Access to materials and infrastructure and production technologies & 0.722 & 22.873 \\
\hline & 37. Increased facilities for water storage & 0.254 & 3.853 \\
\hline & 38. Planning Land Development and Land Use & 0.411 & 6.121 \\
\hline & 39. Integrating macroeconomic and strategic decisions in the field of drought management & 0.523 & 10.939 \\
\hline & $\begin{array}{l}\text { 40. The existence of a long-term national strategy for managing drought and incorporating } \\
\text { environmental and local conditions }\end{array}$ & 0.318 & 3.787 \\
\hline & $\begin{array}{l}\text { 41. Proper cooperation with international institutions to benefit from experiences and abili- } \\
\text { ties }\end{array}$ & 0.490 & 9.493 \\
\hline & $\begin{array}{l}\text { 42. Development of infrastructure and provision of supportive services and the development } \\
\text { of social security in vulnerable areas }\end{array}$ & 0.494 & 10.075 \\
\hline & 43. Coordinating drought crisis management with other national and provincial policies & 0.550 & 16.551 \\
\hline & 44. Identification and proper use of other water resources within the range & 0.397 & 5.598 \\
\hline
\end{tabular}

In Smart-Pls software, the value of critical values (T) indicates the significance of the effects of the variables. If the value of the critical values is greater than 1.96 , there is a significant, positive effect. If it ranges from 1.96 to 1.96 , there is no effect, and if it is smaller than 1.96 , it has a negative effect, but it is significant. According to Figures 3 and 4, it can be stated that the economic dimension of the route, on drought management, with a coefficient of 17.642 , indicates the economic significance of the drought management at a confidence level of 0.95 , and an error of 0.05 . The path coefficient between these two is 0.251 , which suggests that the economic dimension directly explains the management of drought by $0.251 \%$. Also, the social dimension, with a value of $23.999 \mathrm{~T}$, a path coefficient of 0.351 , an environmental dimension with a value of 23.449 , a path coefficient of 0.168 , and an institutional dimension-substructure with a value of $32.421 \mathrm{~T}$, a path coefficient of 0.381 , $0.351,0.168$ and 0.381 percent, directly explain drought management.

\section{General test of the model}

In modeling of structural equations, using the Pls method, in contrast to the covariance method, there is no index for the general measurement of the model. But an index called Good Fit (GOF) was proposed by Tenenhaus et al. (2005). This index takes into account both the measurement and structural models and serves as a benchmark for measuring the overall performance of the model. The limit of this index is between zero and one. Watzles et al. (2009) presented three values of 0.01, 0.25 and 0.36 , respectively, as weak, moderate and strong values for GOF. This index is calculated as an average of $\mathrm{R}^{\wedge} 2$, and the average of the collective values index is manually calculated:

\section{$\mathrm{GOF}=\sqrt{\text { avrage }}($ Comunalitie $) * \mathrm{R}^{\wedge} 2$}

This multiplication factor is two, the average value of the commonality, and the average R square.

The GOF index of this model is 0.5739 , which is indicative of the overall utility of the model.

\section{The quality of the structural model}

The quality of the structural model is calculated by the redundancy index, or the cumulative validity of the cross-flow validity. The purpose of this indicator is to 
examine the ability of the structural model to be predicted by the method of blindness (blindfolding). If all the values obtained are positive for the redundancy index and the validity of the subscription, considering the hidden variables, the structural model is of good quality. According to Figure 5, the results of the model software graphics are positive for model variables, and their quality is proven (Mohsenin \& Esfidani, 2017: 266).

\section{Discussion}

Foundation Data Theory, a systematic approach to data collection and inductive analysis, aims to build a theo-

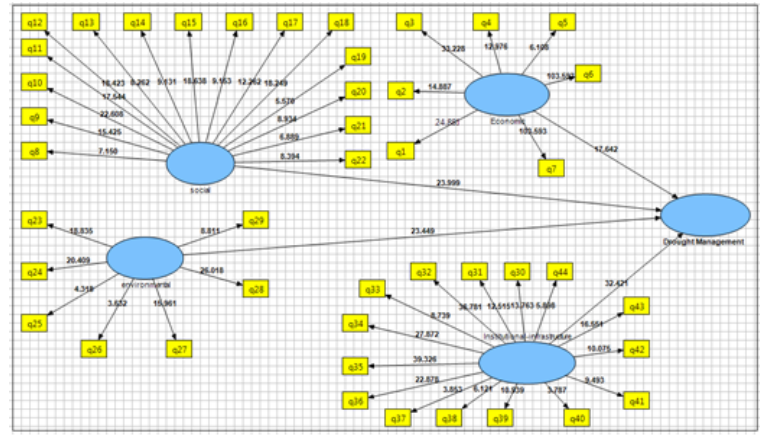

Figure 3. T-Test Results in Drought Management in Rural Areas retical model that provides a better explanation of the data collected. Accordingly, the drought management model is presented in the framework of the foundation data method.

The steps and how to design a drought management model are discussed below.

\section{- Open coding}

At the stage of open coding, the concepts were named without any restrictions on the number of codes. Similar concepts were identified and then grouped together.

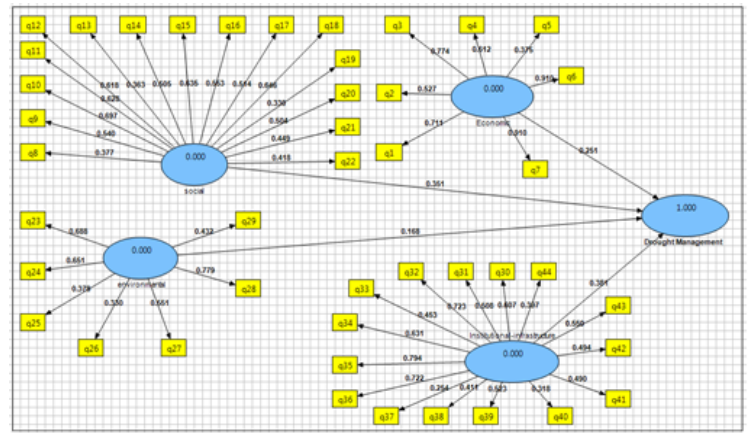

Figure 4. Structural coefficients of drought management model, in rural areas with path JSRD coefficients

Sig is the abbreviation for 'significant' that shows and measures the difference between variables through the significance level of less than 0.05 .

Table 4. Shares

\begin{tabular}{ccc}
\hline Variable & Shared values & The coefficient of determination \\
\hline Economic & 0.507454 & 1.00 \\
Social & 0.270926 & $0.5739=1.00 *$ v0.329395 \\
Environmental & 0.320910 & \\
Institutional-infrastructure & 0.297124 & \\
Drought Management & 0.240565 & $0.5739=$ GOF \\
Average & 0.329395 &
\end{tabular}

Source: (Research Findings, 2019)

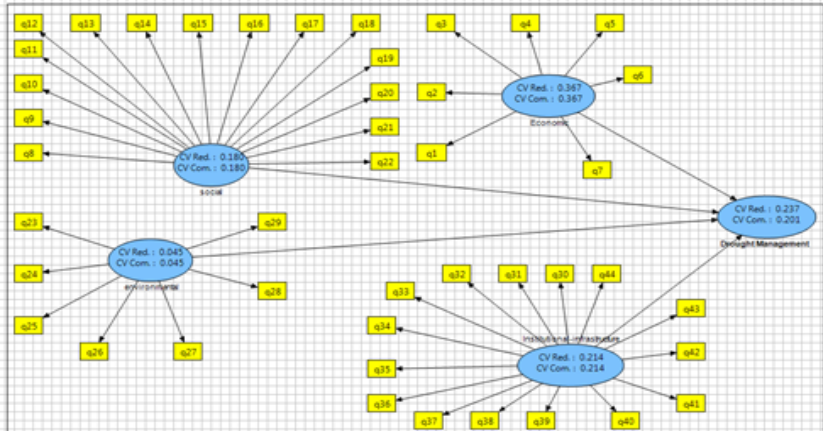

Figure 5. Redundancy or Redundancy Index and Credibility Validity for Drought Management. Source: (Research Findings, 2019) 
It should be noted that in addition to the researcher, other individuals participated in coding and interpreting the data and assisted in the analysis process (supervisor, advisor, two questioners, and one reviewer). Finally, the non-relevant points and comments were eliminated, and the key points were coded into 44 important concepts (Table 5).

\section{Axial coding}

At the axial coding stage, related concepts and expressions were grouped into similar categories and finally formed to explain the four-story drought management pattern, or category.

Axial coding can identify relationships and ratios between categories. In fact, by identifying them, we place the phenomenon in the context in which the event in question takes place. In other words, we place the phenomenon within our own structure. This is done by a template.

Table 5. Concepts derived from the open coder drought management model

\begin{tabular}{|c|c|c|}
\hline Codes & Key phrases & Row \\
\hline E1 & Easy access to goods - Proper use of water and soil & 1 \\
\hline E2 & Appropriate drought management, government-sponsored, government-controlled & 2 \\
\hline E3 & Appropriate jobs & 3 \\
\hline E4 & Various sources of production-associated - no opposition plans & 4 \\
\hline E5 & Providing the necessary credits & 5 \\
\hline E6 & Facilitation - Low interest and grants & 6 \\
\hline E7 & Subsidy payments - Investment support - Entrepreneurship support & 7 \\
\hline S1 & Rural participation & 8 \\
\hline S2 & Existence of social institutions & 9 \\
\hline S3 & Background to drought consequences & 10 \\
\hline S4 & The process of transformation from traditional farming and animal husbandry to new ways & 11 \\
\hline S5 & Suitability of common use methods in villages & 12 \\
\hline S6 & Existence of irrigation system - infrastructure required in agriculture & 13 \\
\hline S7 & High level of knowledge, skills and technology of farmers & 14 \\
\hline S8 & Harvesting of Drought-resistant Cultivars - Changing Crop Pattern & 15 \\
\hline S9 & Improving educational programs & 16 \\
\hline S10 & Native knowledge development & 17 \\
\hline S11 & Increasing investment incentives among locals & 18 \\
\hline S12 & Preventing the disintegration of unity among the villagers & 19 \\
\hline S13 & Promoting and Training Techniques - Proper Circulation and Irrigation Water Consumption Methods & 20 \\
\hline S14 & Development of infrastructure compatible with local conditions & 21 \\
\hline S15 & Exploiting the capacity of research institutes & 22 \\
\hline N1 & Rebuilding and optimizing existing resources and maintaining them & 23 \\
\hline N2 & Preventing water loss - Preventing inappropriate consumption practices & 24 \\
\hline N3 & Water storage management & 25 \\
\hline N4 & Enhancing protected areas - Preventing destruction of vegetation & 26 \\
\hline N5 & Preventing soil erosion & 27 \\
\hline N6 & Combating pest infestations and plant diseases & 28 \\
\hline N7 & Diversity of plant species - Drought resistant plants & 29 \\
\hline 11 & A comprehensive strategic plan for the National Drought Plan & 30 \\
\hline 12 & Development of Drought Management Infrastructure & 31 \\
\hline 13 & Replacing coping techniques, and alternative methods to drought & 32 \\
\hline 14 & Estimating the time of drought, using the devices & 33 \\
\hline
\end{tabular}


Table 5. Concepts derived from the open coder drought management model

\begin{tabular}{ccc}
\hline Cods & Key phrases \\
\hline 15 & Determination of ownership practices of production resources (such as pasture and arable lands) \\
16 & Access to materials, infrastructure and production technologies \\
17 & Increase water storage facilities \\
18 & Land Development and Land Use Planning \\
19 & Integrate macro and strategic decisions in the field of drought management \\
110 & Appropriate collaboration with international organizations to share experiences and capabilities \\
I11 & Providing Support Services - Developing Social Security in Vulnerable Areas \\
I12 & Coordination of drought crisis management with other national and provincial policies \\
I14 & Proper identification and use of other water resources in the area
\end{tabular}

Table 6. Classes and subcategories derived from the axial coding of the drought management model

\begin{tabular}{|c|c|c|}
\hline Under the class & Class & Row \\
\hline \multirow{7}{*}{ economic } & Easy access to goods and services needed for agricultural and handicrafts for proper use of water and soil & 1 \\
\hline & Proper Government Drought Management (Sponsoring - Monitoring-Operating Programs) & 2 \\
\hline & Appropriate, permanent jobs to combat drought & 3 \\
\hline & $\begin{array}{c}\text { The variety of sources of production, with the consequences of the drought, despite the lack of opposition } \\
\text { plans }\end{array}$ & 4 \\
\hline & Providing the necessary funding in the budgeting system for drought management plans & 5 \\
\hline & Provision of low interest and grants facilities and credits to those affected by drought & 6 \\
\hline & Paying subsidies and supporting investment and entrepreneurship in drought-stricken areas & 7 \\
\hline \multirow{15}{*}{ social } & Participation of villagers and nomads in relevant drought planning & 8 \\
\hline & $\begin{array}{c}\begin{array}{c}\text { Existence of social institutions in rural and nomadic areas, for representation of people, including in the field } \\
\text { of drought prevention }\end{array}\end{array}$ & 9 \\
\hline & Background to drought consequences & 10 \\
\hline & The process of transformation from traditional farming and animal husbandry to new ways & 11 \\
\hline & Suitability of common use methods in villages & 12 \\
\hline & The existence of an adequate irrigation system, and the infrastructure needed in the agricultural sector & 13 \\
\hline & High level of knowledge, skills and technology of farmers in water resources management & 14 \\
\hline & Benefit from drought tolerant cultivars and change in cultivation pattern & 15 \\
\hline & Improving extension training programs in water resources management in agriculture & 16 \\
\hline & Native knowledge development & 17 \\
\hline & Increasing investment incentives to combat drought among local people & 18 \\
\hline & Prevent the disintegration of unity between individuals, and rural and nomadic communities & 19 \\
\hline & $\begin{array}{c}\text { Promotion and training of techniques and proper methods of circulation, distribution and consumption of } \\
\text { irrigation water }\end{array}$ & 20 \\
\hline & Development of infrastructure and irrigation and water supply networks compatible with local conditions & 21 \\
\hline & Exploiting the capacity of research institutes, academic centers and executive agencies to address drought & 22 \\
\hline
\end{tabular}


Table 6. Classes and subcategories derived from the axial coding of the drought management model

\begin{tabular}{|c|c|c|}
\hline $\begin{array}{c}\text { Under the } \\
\text { class }\end{array}$ & Class & Row \\
\hline \multirow{7}{*}{ enviromental } & Reconstruction and optimization of existing resources & 23 \\
\hline & Preventing wastage of water and improper use & 24 \\
\hline & Storage of rainwater and snow & 25 \\
\hline & Increase protected areas, and prevent their destruction & 26 \\
\hline & Prevent soil erosion and desertification & 27 \\
\hline & Combating pest infestations, and plant and pasture diseases & 28 \\
\hline & Diversity of plant species, and prevent their extinction & 29 \\
\hline \multirow{15}{*}{$\begin{array}{l}\text { Institutional - } \\
\text { Infrastructure }\end{array}$} & A comprehensive strategic plan for integrated drought management & 30 \\
\hline & Development of Drought Management Infrastructure in Rural and Tribal Areas & 31 \\
\hline & Replacing coping methods and alternatives to drought, rather than the consequences & 32 \\
\hline & Estimation of the time of drought & 33 \\
\hline & The suitability of the public service and insurance systems to combat drought & 34 \\
\hline & Determination of ownership practices of production resources (such as pasture and arable lands) & 35 \\
\hline & Access to materials, infrastructure and production technologies & 36 \\
\hline & Increasing water storage facilities & 37 \\
\hline & Land Development and Land Use Planning & 38 \\
\hline & Integrating macro and strategic decisions in the field of drought management & 39 \\
\hline & Long-term national strategy for managing droughts by incorporating environmental and local conditions & 40 \\
\hline & Appropriate collaboration with international organizations to share experiences and capabilities & 41 \\
\hline & Developing infrastructure and providing support services, and developing social security in vulnerable areas & 42 \\
\hline & Coordination of drought crisis management with other national and provincial policies & 43 \\
\hline & Proper identification and use of other water resources in the area & 44 \\
\hline
\end{tabular}

\section{Selective coding}

At the selective coding stage, one category emerges most prominently in data and interviews (Azizi et al., 2015). This category, which is the central or core category of the present study, was placed at the heart of the other classes, by explaining the pattern as a pivotal phenomenon. The reason for choosing this title is that all the concepts and categories somehow refer to it (Figure 6).

1- What model can be used to manage the drought in the rural areas under study?

Based on the results of the quantitative research model, in the economic aspect of granting low interest grant facilities and credits to those affected by drought with factor load of 0.910 , subsidy payments and investment and entrepreneurship support in drought affected areas with factor load of 0.910 , existence of suitable and permanent jobs to tackle drought with factor load of 0.744 , in the social aspect of reducing the consequences of drought, with factor load of 0.697 , increased investment incen- tives to tackle drought among locals with factor load of 0.646 and benefit of drought tolerant cultivars and change in the cultivation pattern with a yield factor of 0.635, in environmental control of pest influenza and rangeland diseases, 0.779 , functional load, reconstruction and optimization of existing resources, 0.688 , functional load and water conservation prevention, 0.651 , inappropriate consumption practices in institutionalsocial dimensions, components specificity of production resource ownership practices (such as rangeland and arable lands), replacement of droughts and alternatives to droughts, as opposed to its consequences and access to materials and infrastructure, and production technologies with operating loads of $0.794,0.723$ and 0.722 , respectively are effective components of drought management in rural areas.

The implementation process for reaching the final model of the research (Figure 6) was that, in the first research hypothesis, it was examined whether there was a drought in the city. Data from the Main Synoptic Station over a 30-year period from 1976 to 1986 , revealed that 
there were 14 years of droughts with different periods in the studied villages. In the next phase of the research, considering the problems of drought management, relying on the theoretical and practical foundations of the research, and the data from the interviews, open coding was undertaken to extract the key terms needed to provide a drought management model. In the first stage, 44 concepts of open coding were extracted; in the second stage of axial coding, the 4 main categories were 1- economic, 2- social, 3- environmental, and 4- institutionalinfrastructure, respectively; in the selective or selective coding stage, by determining the drought management model of the nuclear category, the basic data method, or drought management model, was presented. Then by integrating the quantitative and qualitative research methods, the final drought management model was designed and explained. According to the results, it can be said that infrastructure indicators with a path coefficient of 0.381 and the social factor with a path coefficient of 0.351 have the most effect on drought management. And the structure and pattern of drought management are largely influenced by two institutional indicators - infrastructure, and social indicators. This model aims to improve all four indicators of drought management.

\section{5.conclusion}

Field research in the region shows that increasing rural populations, as well as rainfall shortages and droughts in recent years, have led to widespread migration in the region, leading to rural depopulation and the security, environmental and economic impacts on the region. In the past 30 years, 1986-2017, 14 years of meteorological drought have occurred in different parts of the district. Based on the results of this study, it was observed that the economical path to drought management, with a 17,642 significance of economic dimension, shows drought management at a confidence level of 0.95 percent. The path coefficient between these two is 0.251 , which suggests that the economic dimension directly explains the management of drought by $0.251 \%$. The social dimension, with a value of 23.999 and a path coefficient of 0.351 , an environmental dimension, with a value of 23.449 and a path coefficient of 0.168 , and an institutional subordinate dimension, with a value of 32.421 and a path coefficient of 0.381 was 0.351 .0 .168 and 0.381 percent, which directly explain drought management. In fact, droughts, having an impact on rural household economies, while endangering the livelihood of the rural households, also have a significant impact on many social interactions and relationships, and the prospect of turning villagers towards false and illegal jobs and increasing victimization creates clashes among the villagers, leading to economic problems on the one hand, and disrupting many social relationships and interactions, on the other hand, and provides an inappropriate and insecure environment for the villagers, which has forced a large number of rural families to leave their homes and migrate to urban areas to find better working conditions and increase the welfare of their families. In fact, field research in the region indicates that increasing rural populations, as well as rainfall shortages and droughts in recent years, have created widespread migration in the region, which has led to rural depopulation of the villages and security, and environmental problems. Drought management, planning and strategic approach can initially create technical, institutional and service infrastructure in the region, which is the basis for preventing drought stress. By creating new technologies in agriculture, providing training to farmers and villagers, successful patterns can be explained. Subsequently, based on the social capacities of the region, which includes indigenous knowledge of agriculture, the proportion of rural areas, the use of local participation, etc., while expanding the management of drought, can help to preserve rural communities, prevent migration and also increase the productivity of agriculture. Practical examples of the effects of drought and lack of effective management have led to a decrease in the population of the Milehsar in Homeil village from 707 in 2006 to 631 in 2016, as well as the decrease of the population of the rural community of Cheshmeh Sangi in Mansouri village from 625 in 2006 to 520 people in 2016. On the other hand, the use of new irrigation methods, as well as the adoption of drought management approaches in the rural community of Changdeh, the village of Homeil, increased its population from 478 people in 2006 to 520 people in 2016, and the population of the rural community of Gavaraneh the village Mansouri increased from 487 in 2006 to 518 in 2016.

The most important factor influencing drought management in rural areas is the social dimension. For this reason, it is possible to reduce the consequences of drought, increase the incentives for investments to cope with drought among the locals, benefit from drought resistant cultivars, change the pattern of cultivation, transform from traditional agriculture and livestock husbandry to new ways, use the appropriate traditional methods of consumption in the countryside, and so on. In sum, these factors have been hand in hand so that the social dimension can have the greatest impact on drought management. In relation to economic factors, lending facilities and low-interest loans for drought-affected groups, subsidies, support for investment and entrepreneurship 
in drought-affected areas, the existence of suitable and permanent jobs to deal with drought, availability of different resources and convenient access to the goods and services needed for agricultural products and handicrafts are of great importance for proper use of water and soil and in managing droughts in rural areas.

In relation to environmental factors, the fight against pest infestations and plant and animal diseases, the rehabilitation and optimization of existing resources, and the prevention of water losses, and inappropriate consumption practices, are among the effects of these factors on drought management. In relation to institutional-infrastructural factors, as the other factor affecting drought management, it can be stated that the identification of methods of ownership of production resources (such as pasture land and crops), the replacement of coping methods, and alternative methods, in contrast to its consequences, access to materials and infrastructure and production technologies, and the proper application of the public services and insurance system, in the area of coping with drought complications, in general, in the management of droughts in rural areas in Eslamabad Gharb and in planning should prioritize influential factors in drought management, as well as special social factors.

The necessary training for villagers, while preserving rural communities, ensures optimal water management and provides efficient and practical models for managing drought and preventing migration, due to the proper application of water resources and increasing agricultural productivity.
The findings of the qualitative model are in line with the research of Kiani Salami et al. (2017), who conducted a study on explaining the social factors of drought and identifying its effects. ANOVA analysis also shows that there is a significant difference in the social effects of drought among the districts. Based on factor analysis, five factors (emotional attachment, social organization, mental health, relationship disturbance, and longing) are found to be due to drought. The results of the study indicate that drought risk management is an appropriate approach to reduce the vulnerability of farmers in economic, social and environmental aspects. Hoseini et al. (2016) in a study explaining the components of drought crisis management in rural and tribal areas of south-east of Iran, and using factor analysis of drought vulnerability factors, five extracted factors including socio-economic drought, livelihood drought, hydrological drought, agricultural drought and meteorological drought explained $42.32,3.19,79.1,9.10$ and $9 \%$ of the variance (88\%, respectively). Factor analysis of drought effects and consequences showed that ecological-ecological, economic-livelihood, social, and psychological consequences accounted for $76.84 \%$ of the variance. Also, factor analysis of drought crisis management mechanisms led to the extraction of five factors. In the present study, meteorological, socioeconomic and agronomic droughts were explained using the experts' opinions, as well as climatic and agricultural data. And this conceptual variation in the concept of drought, rather than a word game, illustrates the complexity of a critical reality and the necessity of a systematic and comprehensive approach to drought management in rural areas.

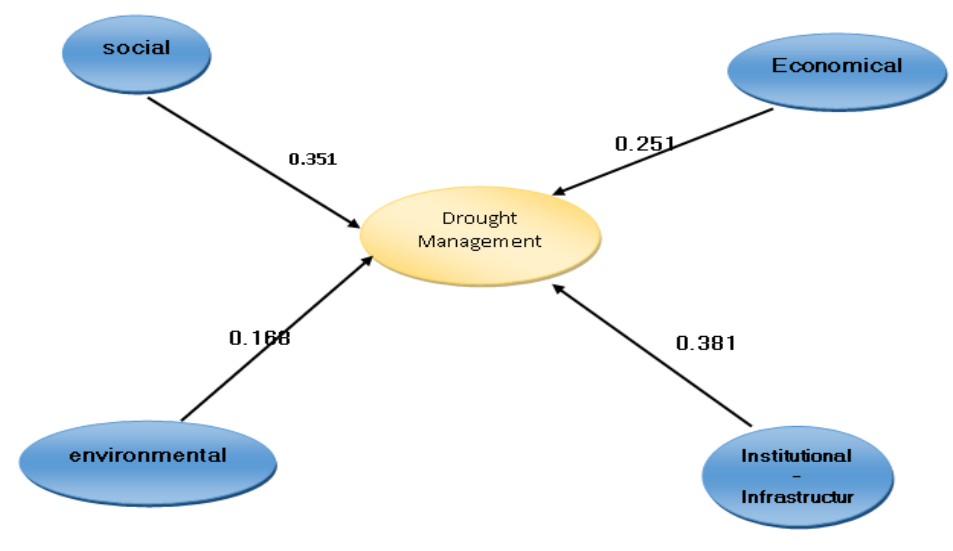

Figure 6. The final model of drought management in rural areas 


\section{Acknowledgements}

This research did not receive any specific grant from funding agencies in the public, commercial, or not-forprofit sectors.

\section{Conflict of Interest}

The authors declared no conflicts of interest.

\section{References}

Adeli, B., Moradi, M., Keshavarz, M., Amirnejad, M. (2014) Drought and its Economic Reflections in Rural Areas, Case: Dodangeh Village in Behbahan district, Rural Economy and Development. 3 (9) ; 131-148

Alipur, H., Charsughi, H., \& Gharib, AS. (2013). Investigating the Effects of Drought on Economic and Soci.1 Status of Farmers, Case Study: Wheat farmers of Nehbandan district. Watershed Studies, No. 99;125-112.

Azizi, A., Sepahvandi, MA., Peyda, N., Mohammadi, J. (2015). Investigating an Effective Approach to Aging: A Study of Foundation Theory, Salem Journal, Volume 10, Number 4; 100-88.

Barghi, H., Bazrafshan, J., Shayan, M. (2018). Analysis and Identification of Drought Effects on Rural Areas (Case Study: Chahga Village, Fereydoun Shahr district), Journal of Environmental Risks, 7(15); 143-162.

Bozarjmehri, K., \& Javanshiri, M. (2015). Identify in Indigenous Knowledge and its Application in Rural Crisis Management by Emphasizing Drought, Flood and Earthquake (Case Study: Zuzan in Khaf Province). Journal of Applied Environmental and Biological Sciences. J. Appl. Environ Biol Sci., 5 (8S); 256263-

Cook, E. R., Seager, R., Cane, M. A., \& Stahle, D. W. (2007). North American drought: Reconstructions, causes, and consequences. Columbia, Journal of Earth-Science, 44 (5); 94-112.

Cooper, PJM, Dimes, J., Rao, KPC, Shapiro, B., Shiferaw, BTwomlow, S. (2008). Coping Better with Current Climatic Variability in Rain-fed Farming Systems of Sub-Saharan Africa: An essential first step in adapting to future climate change? Journal of Agriculture Ecosystems \& Environment, 126; 24-35

Davari, A., Rezazadeh, A. (2016). Structural Equation Modeling, with PLS Software, Publishing Organization, Jihad University, Tehran.

Elfaigh, AHI. (2000). Strategies to Reduce Drought Vulnerability with Special Emphasis on Coping Strategies of the Poor: SubSaharan Semi-arid Region, Western Sudan, Retrieved from World Wide Web: http://www.Wrc.Org. za / wrepublication / wredrought / htmpapers / Elfaig.htm.

Esmaeili, F., Khodadad, M. (2017). Drought risk management, and its effects on the economic recovery of rural farmers; Case study: Bonab city, The Journal of Applied Studies in Management and Development Sciences,. 4; 25-76.

Fard Moradi Nia, S., Soleimanzadeh, A. (2016). "Drought Management, the most important water resource management in Iran, Case study of drought management, focusing on comprehensive drought monitoring system", International Conference on Science and Engineering Research , Turkey, Permanent Secretariat of the Conference, Istanbul University; 125-112.

Folkman, S. (2018). Personal Control and Coping Processes: A theoretical analysis, Journal of Personality and Social Psychology, 46 (4); 839-852.

Fornell, C., \& Larcker, D. (1981). Evaluating structural equation models with unobservable variables and measurement error. Journal of Marketing Research, 18 (1); 39-50.

Gholami, M., Beigi, A., Hoseini, A. (2014). Identifying the Native Methods of Drought Management, Case Study: Sarpol Zahab district, Rural Studies, Vol. 5, No. 3; 611-638.

Hoseini, M., Rusta, K., Zamanpoor, A., Teymuri, M. (2016). Farmers' perception of the drought consequences, with phenomenological approach Case study (South Khorasan province), Quarterly Journal of Agricultural Promotion and Education Research, tenth year / Issue 4 / Winter 95 / Successive $36 ; 70-59$.

Javanmardi, M. (2009). Drought and frostbite, 800 Miliard tomans have been damaged to the province, the newspaper .688 / 5/6, Bakhtar, number 1344

Khamri, J. (2012). Evaluation of Natural Impacts of Drought and Sandstorms on Rural Development, with Emphasis on Disaster Management in Zabol district, Odimi Village, Master's Thesis, Zanjan University, Faculty of Literature and Humanities.

Mohammadi Yeganeh, B., Rezaei Pejand, H., Cheraghi, M. (2012). Drought Effects Analysis, On the Economy of Rural Areas of Abarkuh (During the Period of 1986-2006), Regional Planning: Summer 2012, Volume 2, Number 6; 57-68.

Mohsenin, S., Esfidani, M. (2017). Structural equations based on partial least squares approach, using Smart-PLS (Educational and Applied) software, Publisher, M Book Institute, Mehraban Publishing House, Tehran.

Nagaraja, B. C., Somashekar, R. K., \& Kavitha, A. (2009). Impac of drought on agriculture: challenges facing poor farmers in Karnataka. South India Retrieved from: http: //www.climaseurity.files. wordpress.com

Naveen P., \& Cynthia, B. \& Byjesh, K. (2014). Vulnerability and policy relevance to drought in the semi-arid tropics of Asia A retrospective analysis, Weather and Climate Extremes, 3: 54-61

Peterson, T.C., Hoerling, M.P., Stott, P.A., \& Herring, S.C. (2013) Explaining extreme events of 2012 from a climate perspective. Bulletin of American Meteorological Society, 94 (9); 1-74

Population and Housing Census. (2016). Kermanshah Governorate ,Office of Statistics and Information.

Pour Taheri, M., Raknodin Eftekhari, A., \& Kazemi, N. (2013). The Role of Drought Risk Management Approach in Reducing Socio-Economic Satisfaction of Farmers in Rural Areas 
(From the Point of View of Officials and Experts) Case Study of Solduz Village, West Azarbaijan, Rural Studies, 4; 22-1.

Roshandel Arbatani, T., Pour Ezzat, A., Gholipour, A. (2009). Compilation of a Comprehensive Crisis Management Process Model with Order and Security Approach, Journal of Law Enforcement, No. 2; 82-64.

Rudenko, V., Zayachuk, M., Buchko, Z., \& Ieremia, H. (2017). Agricultural Economies in Ukraine by resource potential aggregate, Human Geographies - Journal of Studies and Research in Human, Volume 11, Issue 2.

Sadeghloo, Ta., Arabteymoti, Y., Shakourifard, E. (2017). Measuring the level of knowledge and awareness of villagers about the management of drought crisis (Case study: rurals of Mian Khaf village, Khaf district), Geography and Environmental hazards, vol. 6, No. 22; 100-73.

Sengestam, L. (2009). Division of Capitals- What role does it play for gender- Differentiated Vulnerability to Drought in Nicaragua? Community Development, 40; 154-176.

Shewmake, Sh. (2008). Vulnerability and the Impact of Climate Change in South Africa's Limpopo River Basin, International Food Policy Research Institute, IFPRI Discussion Paper, Retrieved from: http: // dspace. africaportal.org/js ui / bitstream / 1234567891/31943 // IFPRI\% 20Discussion\% 20Paper\% 2000804.pdf? 1

Sivakumar, M.V.K. (2012). High-level Meeting on National Drought Policy. CSA News, December American Society of Agronomy, Madison, Wisconsin, USA (2012).

Strategic Development Plan of Eslamabad Gharb . (2005). Ministry of the Interior, Kermanshah Governorate.

Tenenhaus, M., Vinzi, V.E., Chatelin, Y.-M., \& Lauro, C. (2005). PLS path modeling. Computational Statistics and Data Analysis, 48 (1); 159-205.

Urkia, A., Fuentes, L., Bis, B., Chir, E., \& Balasz, B. (2008). Development of analytical tools for social, economic and ecological effects of water reuse. Journal of Desalination, 21 (8); 8698

Wetzels, M., Odekerken-Schroder, G., \& Van Oppen, C. (2009). Using PLS path modeling for estimating hierarchical construct models: guidelines and empirical illustration. Management Information Systems Quarterly 33 (1); 11. 
